\title{
Дослідження техніки спортсменів, які спеціалізуються у спортивній ходьбі, на етапах багаторічної підготовки: ретроспективний аналіз та сучасні підходи
}

Сергій Совенко

Національний університет фізичного виховання і спорту України, Київ, Україна

Анотація. Спортивна ходьба - вид легкої атлетики, якому притаманна тенденція до значної інтенсифрікації тренувальної та змагальної діяльності. Тому розробка ефрективної методології технічної підготовки легкоатлетів, які спеціалізуються у спортивній ходьбі, повинна здійснюватися на основі сучасних знань техніки атлетів на етапах багаторічного удосконалення. Мета. Проаналізувати дані науково-методичної літератури, що стосуються техніки спортсменів, які спеціалізуються у спортивній ходьбі, на етапах багаторічної підготовки та визначити основні напрями їі удосконалення. Методи. Аналіз і узагальнення науковометодичної літератури, аналіз статистичних матеріалів виступів спортсменів на змаганнях. Результати. Сучасні дослідження техніки спортсменів, які спеціалізуються у спортивній ходьбі, здійснюється у двох основних напрямах: на змаганнях та в лабораторних умовах. Перші спрямовані переважно на вивчення кінематичних, другі - динамічних характеристик техніки атлетів. Ці дослідження практично не пов'язані з педагогічною складовою (засобами і методами) формування та удосконалення технічної майстерності спортсменів, які спеціалізуються у спортивній ходьбі. Сьогодні практично відсутні дані про техніку спортсменок, які спеціалізуються на дистанції 50 км, а також 35 км у чоловіків та жінок. Мало вивченими залишаються питання техніки спортсменів на етапах попередньої та спеціалізованої базової підготовки. Також відсутні фундаментальні узагальнюючі роботи, присвячені удосконаленню технічної підготовки у процесі багаторічного удосконалення легкоатлетів, які спеціалізуються у спортивній ходьбі. Проаналізовані дослідження, безумовно, створюють фундаментальну базу для удосконалення технічної підготовки у спортивній ходьбі у процесі всієї багаторічної підготовки. Однак вони потребують розширення, систематизації, узагальнення та інтерпретації з позиції насамперед педагогічної складової побудови багаторічного тренувального процесу.

Ключові слова: спортивна ходьба, техніка, технічна підготовка, багаторічна підготовка.

\section{Serhiy Sovenko}

\section{ANALYSIS OF TECHNIQUE IN RACE WALKING ATHLETES AT THE STAGES OF LONG-TERM PREPARATION: RETROSPECTIVE ANALYSIS AND MODERN APPROACHES}

Abstract. Race walking is a track-and-field sport, which is characterized by a tendency to significant intensification of training and competitive activities. Therefore, the development of an effective methodology for technical training of race walking athletes should be based on modern knowledge of athletes' race walking technique at the stages of long-term improvement. Objective. To analyse the data of scientific and methodological literature on the technique of race walking athletes at the stages of long-term preparation and to identify the main directions of its improvement. Methods. Analysis and generalization of scientific and methodological literature, analysis of statistical data on atheltes' performances in competitions. Results. Current studies on the technique of race walking athletes are carried out in two main areas: in competitions and under the laboratory conditions. The first ones are focused primarily on studying the kinematic characteristics, and the second ones are related to the analysis of dynamic characteristics of race walking athletes' technique. These studies are practically unrelated to the pedagogical component

Sovenko S. Analysis of technique in race walking athletes at the stages of long-term preparation: retrospective analysis and modern approaches

Theory and Methods of Physical education and sports. $2021 ; 3: 37-46$

DOI: $10.32652 /$ tmfvs.2021.3.37-46
Совенко С. Дослідження техніки спортсменів, які спеціалізуються у спортивній ходьбі, на етапах багаторічної підготовки: ретроспективний аналіз та сучасні підходи. Теорія і методика фрізичного виховання і спорту. 2021; 3 : $37-46$

DOI: 10.32652/tmfvs.2021.3.37-46
Kong Shue Yan University. 2019. DOl:10.7752 jpes.2020.04223

Надійшла 22.09.2021

Вступ. Сучасний стан розвитку спортивної ходьби характеризується невпинним ростом рівня результатів i, як наслідок, інтенсифікацією тренувального процесу, що вимагає пошуку шляхів оптимізації багаторічної підготовки спортсменів [13].

Одним із пріоритетних напрямів удосконалення сучасної системи багаторічної підготовки легкоатлетів $€$ оптимізація технічної підготовки спортсменів, яка у гармонійному поєднанні 3 фрізичною підготовкою дозволяє досягати високих спортивних результатів в оптимальному віці та у подальшому зберігати високу спортивну майстерність протягом багатьох років $[4,8]$. Проте процес удосконалення технічної підготовки спортсменів на етапах багаторічної підготовки неможливий без детального аналізу техніки виконання змагальної вправи спортсменів різних вікових груп та статі. Тому слід враховувати, що спортивна ходьба - єдиний вид легкої атлетики, до техніки виконання якого ставляться чіткі вимоги правилами змагань, контроль за дотриманням яких здійснюють відповідні судді. Згідно з правилами змагань, у спортивній ходьбі не повинно бути видимої для людського ока фази польоту, або, іншими словами, завжди має бути контакт з опорою, а також винесена вперед (опорна) нога має бути повністю випрямлена в колінному суглобі з моменту першого контакту із землею до проходження вертикалі [12].

Збільшення швидкості спортивної ходьби у провідних спортсменів світу, а разом і тривалості польоту до критичних меж ставлять сьогодні важливі завдання не тільки перед технологією суддівства, а й для тренерів у про- 
(means and methods) of development and improvement of technical skills in race walking athletes. Today there are almost no data on the technique of female athletes competing in $50 \mathrm{~km}$ race walk, as well as of men and women competing in $35 \mathrm{~km}$. The issues of athletes' technique at the stages of preparatory and specialized basic training remain little studied. Furthermore, there are no fundamental generalizing works addressing the improvement of race walking athletes' technical training in the process of long-term improvement. The analyzed studies undoubtedly create a fundamental basis for improving technical training in race walking during the overall process of long-term training. However, they require to be expanded, systematized, generalized, and interpreted primarily from the standpoint of the pedagogical component of designing a longterm preparation process.

Keywords: race walking, technique, technical training, long-term training.

цесі технічної підготовки. Тому відповідні розробки, які б дозволяли тренерам опиратись на об'єктивні дані, сьогодні вкрай необхідні.

В останнє десятиліття відповідні технології розробляються багатьма вченими [22, 28, 43, 50, 53] та апробуються на практиці. Так, Т. Caporaso та S. Grazioso [22] представили алгоритми вимірювання порушень техніки, зібраних одним датчиком, розташованим у поперековому відділі хребта та апробували її на спортсменах високого рівня на різних швидкостях пересування - від 12,0 до 15,5 км · год-1. Цю систему можна використовувати і в тренувальному процесі. Цілком ймовірно, що відповідні технології найближчим часом можуть ввійти в практику суддівства змагань та в тренувальний процес.

Система змагань спортсменів у циклічних видах спорту, пов'язаних 3 проявом витривалості, в процесі багаторічної підготовки має свої особливості, головна серед яких полягає у збільшенні довжини змагальної дистанції. Так, легкоатлети з 11 до 15 років, які спеціалізуються у спортивній ходьбі, змагаються на дистанціях 2 та 3 км, з 16 до 19 років - на дистанції 10 км (у дівчат 16-17 років довжина дистанції становить 5 км), і тільки при досягненні «молодіжного» віку атлети змагаються на класичних для дорослих спортсменів дистанціях - 20 та 50 км. Тому в першій стадії багаторічної підготовки досягнення певного рівня спортивних результатів у спортивній ходьбі не дає достатньо вичерпної інформації, навіть досвідченому тренеру, про ефективність тренувального процесу на тому чи іншому етапі багаторічної підготовки, тобто досягнення спортсменом адекватних віку «цільових завдань» підго- товки. При цьому на перший план повинні висуватись завдання досягнення певних модельних показників техніки виконання змагальної вправи, як в другій стадії багаторічної підготовки поряд 3 великими фізичними навантаженнями стануть основою для досягнення спортивних результатів високого рівня.

Мета дослідження - проаналізувати дані науково-методичної літератури, де йдеться про техніку спортсменів, як спеціалізуються у спортивній ходьбі, на етапах багаторічної підготовки та визначити основні напрями її удосконалення.

Методи дослідження: аналіз і узагальнення науково-методичної літератури, аналіз статистичних матеріалів виступів спортсменів на змаганнях.

Результати дослідження та їх обговорення. Спортивний результат у спортивній ходьбі залежить від ступеня прояву спеціальної витривалості, що визначається можливістю організму тривалий час підтримувати рівномірність між кисневим запитом та його поглинанням, а також від техніки виконання змагальної вправи. Враховуючи значну тривалість змагально вправи, удосконалення технічної майстерності здійснюється практично нерозривно з розвитком витривалості та $€$ одним із найбільш важливих процесів оптимізації багаторічної підготовки в цілому $[17,47]$.

Відомо, що у видах легкої атлетики, пов'язаних 3 проявом витривалості, досягнення максимально можливого результату залежить від підтримання найвищої середньої швидкост проходження протягом усієї дистанції [6].

Результати досліджень деяких учених $[18,19]$ показали, що спортсменам слід уникати дуже високих або дуже низьких швидкостей, що знижує ризик отримання попередження за зігнуте коліно і, відповідно, швидкості по всій довжині дистанції. При цьому більш кваліфіковані та підготовлені атлети здатні підтримувати рівномірний темп протягом усієї дистанції. Тому процес навчання техніки та подальше її удосконалення повинні враховувати відповідні правила вже на початковому етапі багаторічної підготовки. Складність полягає і в тому, що рівень розвитку фрізичних якостей не завжди відповідає техніці виконання змагальної вправи. Так, наприклад, порівнюючи дані техніки спортсменів-юніорів [37] та провідних спортсменів світу [40], приходимо до висновку, що вже на базових етапах багаторічної підготовки тривалість польоту досягає рівня 0,03-0,05 с, що є граничними величинами при зоровому його виявленні та поряд 3 недосконалою технікою [29] часто призводить до дискваліфікації юних спортсменів у ході змагань.

3 іншого боку, дослідження A. Harrison зі співавт. [38] показали, що спортсмени високої кваліфрікації адаптували свою техніку ходьби для використання періодів польоту 0,04 c, які неможливо виявити для людського ока. У досвідчених спортсменів, на відміну від початківців, ці короткотривалі фрази польоту спостерігаються навіть на відносно повільних швидкостях ходьби. Співвідношення максимальної швидкості ходьби з періодами польоту 0,04 с до прогнозованої максимальної швидкості може забезпечити корисний показник технічної майстерності, який можна використовувати для розрізнення початківців та досвідчених атлетів. Цей індекс може також мати потенціал для моніторингу зміни результативності або ідентифрікації талантів.

Швидкість переміщення у спортивній ходьбі залежить від довжини і частоти кроків. Пошук шляхів збільшення, а також оптимального співвідношення цих параметрів $€$ основою технічного вдосконалення спортсменів [14]. Р. А. Абзалов [1], аналізуючи думки тренерів і фрахівців з бігу на витривалість 3 приводу цього питання, не знаходить єдиної думки: вико- 
ристовуючи який показник - частоту або довжину бігового кроку - спортсмени показують високі або рекордні результати.

С. В. Калитка зі співавт. [9], порівнюючи дані довжини і частоти кроків у чоловіків та жінок під час проходження 1000 м в аеробно-анаеробному режимі, 500 м в анаеробно-аеробному режимі і 200 м в анаеробному режимі порівняно з 1000 м, які спортсмени проходили в аеробному режимі, прийшли до таких висновків. У чоловіків збільшення швидкості на всіх дистанціях здійснюється за рахунок збільшення частоти і більшою мірою довжини кроку. У жінок під час проходження дистанції 1000 і 500 м частота кроків дещо зменшується і підвищення швидкості компенсується довжиною кроку, під час проходження 200 м дистанції істотно підвищуються і частота (до рівня критичної) довжина кроків. Зокрема, у чоловіків приріст швидкості $(55,67$ \%) здійснюється за рахунок збільшення приросту частоти кроків (12,84 \%) і, більшою мірою, - довжини кроків (38,74\%). у жінок приріст швидкості $(17,48$ і $32,17 \%$ здійснюється за рахунок збільшення довжини кроків $(16,26$ і $35,92 \%)$ при зниженні частоти кроків $(-1,14$ і $-0,68 \%)$, а приріст швидкості $(46,50 \%)$ - за рахунок збільшення як довжини кроків (42,72\%), так і їх частоти $(18,21 \%)$. Загалом у жінок порівняно з чоловіками приріст швидкості здійснюється більшою мірою за рахунок збільшення довжини кроку. Учені припускають, що це пов'язано 3 анатомічною будовою тіла жінки, розвиненішою гнучкістю, еластичністю зв'язок опорно-рухового апарату.

G. Pavei зі співавт. [45], аналізуючи науково-методичну літературу останніх років, що стосується техніки спортивної ходьби, виділили три основні напрями досліджень: кінематика, сила реакції опори та потужність і есрективність.

Збільшення рівня результатів та конкуренції на найбільших світових форумах постійно привертає інтерес науковців до досліджень техніки змагальної діяльності провідних спортсменів світу. Аналіз їхніх результатів дозволив Г. І. Корольову [10] вста- новити модельні характеристики для досягнення показників рівня рекордів світу. Так, у спортивній ходьбі на 20 км у чоловіків для досягнення результату 1:17.20 (середня швидкість - 4,31 м · $\mathrm{c}^{-1}$ ) показники довжини кроків під час подолання дистанції повинні бути в межах 1,22-1,24 м при частоті кроків 3,50-3,51 крок · c $^{-1}$ (близько $210 \mathrm{kрок} \cdot \mathrm{c}^{-1}$ ). У спортивній ходьбі на 50 км у чоловіків для досягнення результату 3:35.00 (середня швидкість $\left.-3,88 \mathrm{~m} \cdot \mathrm{c}^{-1}\right)$ : довжина кроку - 1,19-1,21 м, а частота - 3,213,24 крок $\cdot \mathrm{c}^{-1}$. У жінок для досягнення результатів, близьких до 1:24.00 (середня швидкість - 3,97 м · $\mathrm{c}^{-1}$ ) - довжина кроку - 1,18-1,19 м, а частота - 3,32-3,39 крок · c $^{-1}$.

Дослідженням техніки провідних спортсменів світу, які спеціалізуються у спортивній ходьбі, присвячені роботи В. Hanley зі співавт. [34-36]. За результатами їхніх досліджень на Кубку Європи зі спортивної ходьби у 2007 р. $[34,35]$ було встановлено кінематичні характеристики техніки і морфологічні показники найсильніших спортсменів світу. Так, зріст і маса тіла у жінок, які спеціалізуються на дистанції 20 км, становить 1,64 м $( \pm 0,05)$ та 51 кг ( \pm 5$)$, у чоловіків, які спеціалізуються на дистанціях 20 та 50 км відповідно - 1,80 м $( \pm 0,06)$ і 67 кг $( \pm 5)$ та 1,78 м $( \pm 0,08)$ і 67 кг $( \pm 6)$. У спортивній ходьбі на 20 км у жінок для досягнення середньої швидкості 13,29 $( \pm 0,78) \mathrm{KM} \cdot$ год $^{-1}$ середні показники довжини кроків під час подолання дистанції становили 1,08 м $( \pm 0,05)$ при частоті кроків 3,41 крок $\cdot \mathrm{c}^{-1}$ $( \pm 0,12)$. У чоловіків на цій дистанції для досягнення середньої швидкості $14,80( \pm 0,52)$ км · год ${ }^{-1}$ середні показники довжини кроків під час подолання дистанції становлять 1,23 м ( $\pm 0,05)$ при частоті кроків 3,35 крок $\cdot \mathrm{c}^{-1}$ $( \pm 0,13)$. На дистанції 50 км середня швидкість 14,14 ( \pm 0,55) - 1,22 м $( \pm 0,06)$ та 3,23 крок $\cdot \mathrm{c}^{-1}( \pm 0,17)$.

Провідні радянські спеціалісти зі спортивної ходьби А. Л. Фруктов та Ю. Г. Травін [17] встановили, що перехід ходьби у біг у спортсменів високої кваліфікації здійснюється при швидкості близько 4,45 м $\cdot \mathrm{c}^{-1}$
(16,02 км · год $\left.{ }^{-1}\right)$, довжині кроків 1,25 м і частоті $214 \mathrm{kpoK} \cdot \mathrm{XB}^{-1}$.

Орієнтований на тренера аналіз спеціальної літератури підкреслює, що довжина кроку для збільшення швидкості є більш важливою, ніж частота, і вона в основному отримується за рахунок сили надп'ятковогомілкового та кульшового суглобів [45].

Спортивна ходьба входить до циклічних видів легкої атлетики. Один цикл складається 3 подвійного кроку: лівою і правою ногою. У циклі $є$ два періоди одиночної і два - подвійної опори, які чергуються $[17,42]$. Для більш наочного уявлення про структуру рухів у фазах виділяють моменти дій - такі миттєві положення, після яких відбувається зміна рухів, тобто моменти є межами зміни рухів в одній або кількох ланках. Для переважно невербального (візуального) сприйняття зміни рухів у той або інший момент виділяють пози - опис положень ланок тіла відносно загального центру маси (ЗЦМ) тіла або одне одного [5].

У кожному періоді одиночної опори виділяють дві фрази - задній і передній крок. Фаза заднього кроку починається 3 моменту відриву ноги від опори до моменту вертикалі, який визначається знаходженням ЗЦМ тіла точно під центром тиску на площу опори. Фаза переднього кроку починається з моменту вертикалі до постановки ноги на опору [2].

У кожній з цих фраз окрім перенесення вільної (махової) ноги важливо виділити взаємодію з ґрунтом опорної. Так, у фразі заднього кроку опорна нога виконує переднє відштовхування, у фразі переднього кроку - заднє відштовхування [17].

Тривалість одиночної опори у висококваліфікованих спортсменів залежно від їхніх індивідуальних особливостей становить близько 0,260,28 с [32, 40]. При цьому слід відмітити той факт, що за рахунок зменшення часу амортизації зменшується час відштовхування. Так, тривалість амортизації (переднього відштовхування) у фразі заднього кроку становить близько 0,10-0,12 с, у фазі переднього кроку час взаємодії з опорою, 


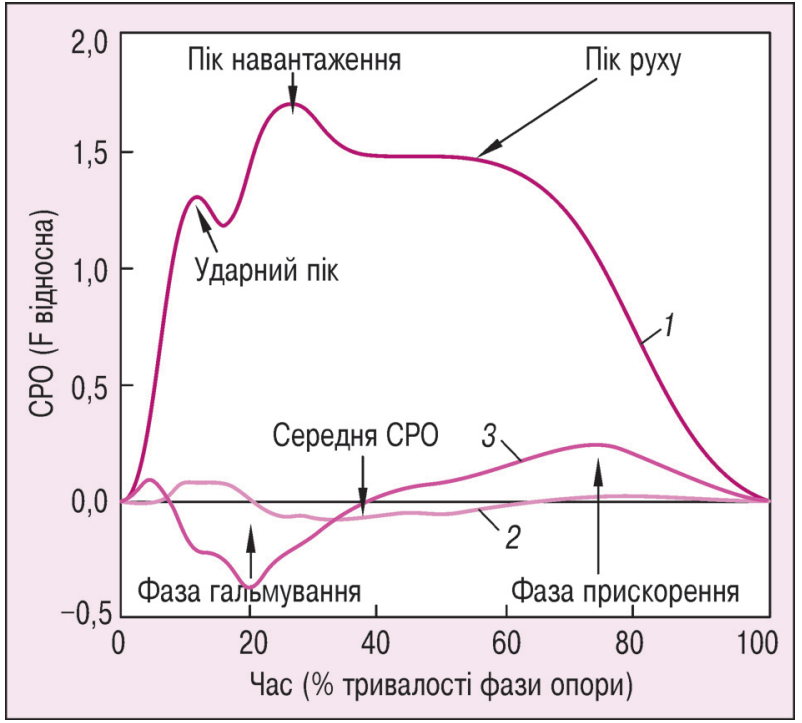

1 - вертикальна; 2 - передньо-задня; 3 - медіально-латеральна (медіально-бокова)
Рисунок 1 - Типова схема взаємодії спортсмена з опорою: складові сили реакції опори (СР0) (за B. Hanley [32]): тобто тривалість заднього відштовхування - 0,16-0,18 с [48].

Джерелом руху у спортивній ходьбі виступає робота м'язів. За рахунок м'язових скорочень (взаємодії внутрішніх сил) відбувається відштовхування, внаслідок чого спортсмен просувається вперед. Під час спортивної ходьби на людину діють зовнішні сили - реакції опори, тяжіння, опору середовища. Зважаючи на той факт, що цей вид легкої атлетики здійснюється практично по горизонталі на відносно невисокій швидкості, то силу тяжіння й опору зовнішнього середовища можна не враховувати, при цьому важливо розглядати силу реакції опори, яка виникає у відповідь на дію на неї спортсмена. За величиною вона дорівнює силі дії на опору і протилежна по напрямку руху. Таким чином, у фазі заднього кроку під час переднього відштовхування сила реакції опори спрямована проти руху спортсмена, тобто виступає джерелом гальмування [7]. При цьому відбувається амортизація руху переважно за рахунок поступальної роботи м'язів передньої частини гомілки опорної ноги, а також унаслідок опускання таза у бік махової ноги і деякого опускання рук (збільшення кута в ліктьовому суглобі). У цей час тіло спортсмена просувається за інерцією.

Для того, щоб зменшити негативну дію сили реакції опори в цій фразі, потрібно здійснювати постановку ноги ближче до проекції ЗЦМ тіла, тобто під кутом, близьким до 90․ Але не слід забувати, що в результаті таких дій зменшується довжина кроку, що, у свою чергу, може спричинити погіршення спортивного результату [15].

Потрібно зазначити, що між довжиною і частотою кроків існує взаєм0зв'язок: надмірне збільшення темпу кроків зменшує їх довжину, і навпаки, збільшення довжини зменшує їх частоту, що може знизити швидкість пересування. Під час відштовхування у фазі переднього кроку сила реакції опори спрямована вперед-угору, що сприяє просуванню ЗЦМ тіла вперед.

Важливо зазначити, що всі рухи біоланок тіла здійснюються 3 прискоренням, унаслідок чого виникають інерційні сили: одні надають швидкості усьому тілу, інші нейтралізують негативну їх дію.

K. Hoga-Miura, R. Hirokawa, M. Sugita [40], проаналізувавши техніку провідних спортсменів світу, які спеціалізуються у спортивній ходьбі на 20 км, на Іграх Олімпіади 2004 р. та чемпіонаті світу 2005 р., змоделювали можливість збереження швидкості при скороченні тривалості польоту за рахунок збільшення часу фази активного відштовхування при збільшенні обертального моменту в колінах та стегнах ноги, що переноситься. Досліджуючи техніку спортивної ходьби жінок на дистанції 20 км на чемпіонатах світу 2005 та 2007 рр., учені [41] констатували, що приско- рення центру ваги відносно центру тиску корелювало зі швидкістю ходьби та часом опори. Велике прискорення центру ваги відносно опорної стопи спричиняється прискоренням стегна опорної ноги та стегна ноги, що переноситься в середині опорної фрази, що також залежить від збільшення обертального моменту в колінах. I це не дивно, адже ще М. О. Бернштейн [3] вказував, що коліну характерний рекордний для всіх зчленувань людського тіла розмах згинання і розгинання - близько $140^{\circ}$ активної рухливості і понад $170^{\circ}$ пасивної. При цьому колінний суглоб (півзігнутий) допускає ще невелике поздовжнє обертання гомілки (на 40-60). Важливість прискорення опорної ноги та активного маху стегна ноги, що переноситься, підтверджено і дослідженнями W. Sun, L. Zhang, A. Fan [49].

Дослідження G. Dona зі співавт. [25] також підтверджують важливість оцінювання сагітального кута в колінному суглобі та результуючого моменту як основи оцінювання техніки спортсменів. При цьому спостерігаються й індивідуальні особливості окремих атлетів.

Під силою відштовхування потрібно розуміти силу реакції опори, що виникає під впливом м'язових зусиль і інерційних сил на опору. При цьому важливим $є$ пошук оптимальних параметрів взаємодії з опорою під час спортивної ходьби на різних швидкостях $[33,46]$.

У фазі заднього кроку під час переднього відштовхування вертикальна складова сили реакції опори, за різними даними, коливається в діапазоні 88-150 кг. Водночас під час відштовхування у фразі переднього кроку показники вертикальної складової сили реакції опори дещо нижчі - на 15-20 \%, ніж під час переднього відштовхування і можуть перебувати в діапазоні 69-137 кг [6, 17].

Типову схему взаємодії спортсмена з опорою представлено на рисункy 1.

Спортивна ходьба $є$ вправою без високих ударних навантажень, пов'язаних 3 бігом. J. Norberg та A. Schmitz [44] встановили, що ступінь навантаження вертикальної сили 
Т а б л и ц я 1. Індивідуальні кінематичні характеристики техніки спортсменів високого світового рівня, які спеціалізуються у спортивній ходьбі

\begin{tabular}{|c|c|c|c|c|c|c|c|c|c|}
\hline \multirow{4}{*}{ Показник } & \multicolumn{9}{|c|}{ Стать, дистанція, місце на Кубку світу } \\
\hline & \multicolumn{6}{|c|}{ Чоловіки } & \multirow{2}{*}{\multicolumn{3}{|c|}{$\begin{array}{c}\text { Жінки } \\
20 \text { км }\end{array}$}} \\
\hline & \multicolumn{3}{|c|}{$20 \mathrm{kM}$} & \multicolumn{3}{|c|}{$50 \mathrm{kM}$} & & & \\
\hline & 3 & 15 & 40 & 1 & 14 & 31 & 1 & 17 & 37 \\
\hline Зріст, м & 1,76 & 1,75 & 1,82 & 1,74 & 1,71 & 1,72 & 1,60 & 1,63 & 1,60 \\
\hline Швидкість, км · год ${ }^{-1}$ & 15,75 & 15,19 & 13,98 & 14,49 & 13,61 & 12,75 & 14,79 & 13,34 & 12,06 \\
\hline Довжина кроку, м & 1,24 & 1,26 & 1,20 & 1,20 & 1,13 & 1,10 & 1,19 & 1,09 & 1,00 \\
\hline $\begin{array}{l}\text { Співвідношення довжини кроку } \\
\text { до зросту, \% }\end{array}$ & 70,3 & 71,9 & 65,9 & 69,2 & 66,3 & 63,9 & 74,1 & 67,0 & 62,6 \\
\hline Частота кроків, крок $\cdot \mathrm{c}^{-1}$ & 3,54 & 3,35 & 3,24 & 3,34 & 3,33 & 3,22 & 3,47 & 3,39 & 3,35 \\
\hline Довжина переднього кроку, м & 0,37 & 0,36 & 0,40 & 0,37 & 0,38 & 0,37 & 0,36 & 0,31 & 0,33 \\
\hline $\begin{array}{l}\text { Співвідношення довжини перед- } \\
\text { нього кроку до довжини кроку, \% }\end{array}$ & 20,7 & 20,3 & 21,7 & 21,3 & 21,9 & 21,5 & 22,5 & 19,0 & 20,6 \\
\hline Довжина заднього кроку, м & 0,47 & 0,48 & 0,50 & 0,51 & 0,48 & 0,43 & 0,46 & 0,43 & 0,39 \\
\hline $\begin{array}{l}\text { Співвідношення довжини задньо- } \\
\text { го кроку до довжини кроку, \% }\end{array}$ & 26,4 & 27,4 & 27,2 & 29,3 & 28,1 & 25,0 & 28,8 & 26,4 & 24,4 \\
\hline Довжина польоту, м & 0,27 & 0,26 & 0,16 & 0,17 & 0,16 & 0,18 & 0,23 & 0,15 & 0,11 \\
\hline Довжина переходу опори, м & 0,15 & 0,16 & 0,17 & 0,15 & 0,13 & 0,13 & 0,16 & 0,18 & 0,16 \\
\hline Кут повороту таза, град. & 16 & 16 & 13 & 18 & 15 & 16 & 15 & 10 & 16 \\
\hline Кут повороту плечей, град. & 17 & 17 & 20 & 17 & 17 & 13 & 26 & 19 & 16 \\
\hline $\begin{array}{l}\text { Кут у колінному суглобі в момент } \\
\text { постановки ноги на грунт, град. }\end{array}$ & 179 & 181 & 182 & 179 & 179 & 184 & 183 & 177 & 181 \\
\hline $\begin{array}{l}\text { Кут у колінному суглобі в момент } \\
\text { вертикалі, град. }\end{array}$ & 186 & 187 & 187 & 187 & 181 & 190 & 191 & 187 & 193 \\
\hline
\end{tabular}

реакції опори під час спортивної ходьби на 46 \% нижчий, ніж під час бігу.

У періоді подвійної опори виділяють фразу переходу опори, яка починається з моменту постановки однієї ноги на опору і закінчується зняттям з опори іншої. Тривалість цієї фрази у спортсменів високої кваліфікації становить 0,01-0,005 с [17], сьогодні вона властива тільки юним спортсменам на початкових етапах багаторічної підготовки. На сучасному етапі розвитку спортивної ходьби спортсменам високої кваліфікації властива фраза польоту, тривалість якої 0,03-0,04 с, що становить складність для суддівства, оскільки за її наявністю судді візуально визначають, іде чи біжить спортсмен [21, 32].

Одну з головних ролей у розвитку техніки спортивної ходьби відіграють рухи в кульшовому суглобі, які здійснюються в усіх площинах. У процесі ходьби нахил таза вперед то збільшується, то зменшується (середина одиночної опори). Нахил таза вперед дозволяє спортсменові зробити «довше проштовхування». Під час перенесення ноги вперед таз опускається в її бік. До кінця відштовхування він повертається в кульшовому суглобі опорної ноги в їі бік. Найбільшого значення слід надавати руху таза навколо вертикальної осі, що дозволяє збільшити довжину кроку [5].

Урівноваження руху ніг і таза відбувається за рахунок повороту плечового пояса і таза в протилежних напрямках, що також дозволяє зменшити ступінь відхилення ЗЦМ тіла від прямолінійного просування і підвищує м'язові зусилля за рахунок попе- реднього розтягування м'язів і збільшення амплітуди їх скорочення [17].

Результати досліджень К. НogaMiura зі співавт. [39] показали, що у спортсменів високого світового рівня момент сили правого плеча і обертальний момент у лівому плечі безпосередньо перед відривом правої ноги суттєво корелювали зі швидкістю ходьби. Отже, обертальний момент плеча має функцію урівноваження обертального моменту тулуба для швидкої ходьби з великим механічним потоком енергії.

Для досягнення високої швидкості й економічності спортивної ходьби велике значення має прямолінійність поступального руху тіла спортсмена. Ї̈̈ ступінь характеризує траєкторія ЗЦМ тіла. При правильній спортивній ходьбі крива його вертикальних 
коливань вища в момент перед двоопорним положенням, проте в цілому траєкторія ЗЦМ тіла наближається до прямої лінії - амплітуда вертикальних переміщень коливається в діапазоні 2,9-4,3 см [16].

У момент вертикалі зниження ЗЦМ тіла досягається провисанням таза відносно кульшового суглоба опорної ноги. У цей момент лінія, що сполучає кульшові суглоби, нахилена, а коліно махової ноги значно нижче від коліна опорної. Проте цей рух не має бути домінуючим, оскільки збільшує хвилеподібність шляху ЗЦМ тіла. Під час переходу в двоопорне положення підняття стегна махової ноги і подальше відштовхування стопою опорної ноги підвищують висоту ЗЦМ тіла [2].

Для уникнення бічних відхилень ЗЦМ тіла від прямолінійного шляху стопи потрібно ставити внутрішнім краєм впритул до умовної прямої лінії, або на лінію, і в окремих випадках, залежно від індивідуальних особливостей спортсменів, - дещо розвернутими [17].

Під час ходьби на крутих схилах виникає небезпека переходу на біг. Щоб уникнути цього, спортсмени зазвичай знижують швидкість, зменшуючи довжину кроку і відхиляючи тулуб трохи назад [15].

У результаті досліджень на Кубку світу зі спортивної ходьби 2008 р. B. Hanley [32] вдалося встановити найбільш інформативні кінематичні показники техніки, що впливають на досягнення результатів, та їх величини у спортсменів високого світового рівня (табл. 1).

Окрім ключових довжини та частоти кроків він виділив такі показники: довжину основних складових кроку переднього та заднього кроку, польоту, переходу опори; співвідношення довжини кроку до зросту; співвідношення переднього та заднього кроку до загальної довжини кроку; кути повороту таза та плечей, кути у колінному суглобі в момент постановки ноги на ґрунт та у момент вертикалі.

Сучасні підходи до вимірювання основних складових довжини кроку представлено на рисунку 2.

Загалом по ходу долання дистанції у одних спортсменів знижен-
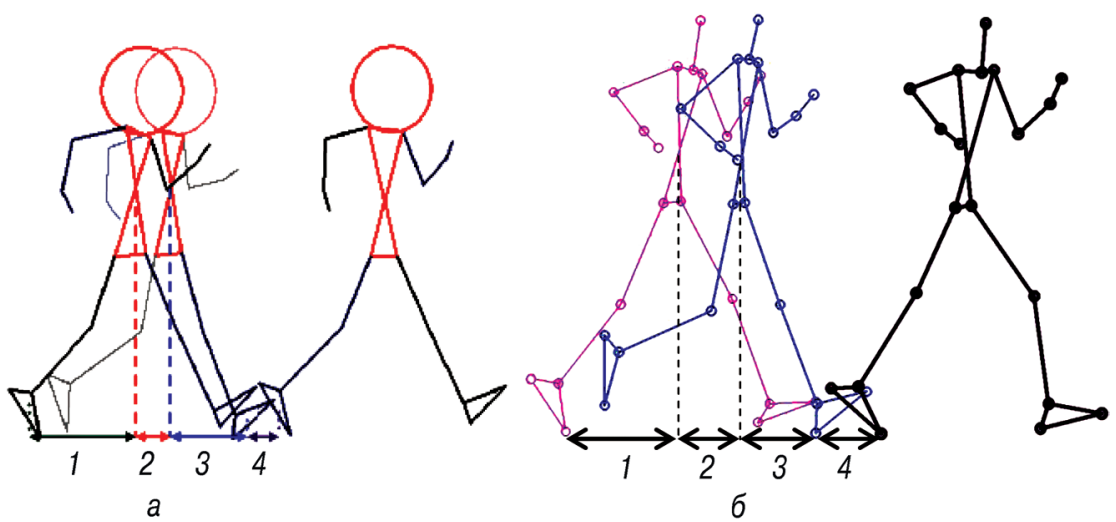

Рисунок 2 - Підходи до вимірювання основних складових довжини кроку:

1 - задній крок; 2 - дистанція польоту; 3 - передній крок; 4 - перехід опори (довжина стопи) (за: $a$ - Hanley [32]; б-Sovenko [48])

ня швидкості обумовлене переважно зменшенням довжини кроків, у інших - як їх довжини, так і частоти. В атлетів більш низької кваліфікації зниження швидкості обумовлене зазвичай зменшенням довжини кроків і навпаки у спортсменів високого світового рівня підвищення або збереження швидкості здійснюється переважно за рахунок збільшення довжини кроків $[11,13]$.

Важливо зазначити, що необхідно пам'ятати, що швидкий початок дистанції може призвести до значного зниження швидкості навіть у спортсменів високого світового рівня [52].

W. Chwała, A. Klimek, W. Mirek [24] встановили значну різницю в енергозатратах спортсменів високого рівня при змагальній швидкості порівняно зі спортивною ходьбою 3 «технічною» швидкістю. Так, сумарні затрати енергії під час ходьби 3 «технічною» швидкістю становили 51,2 кДж · $\mathrm{M}^{-1}$, а 3 змагальною - 78,3 кДж · М $^{-1}$. При цьому незалежно від швидкості загальна зовнішня робота м'язів станови ла $25 \%$ загальної. Загальна зовнішня робота в основному збільшувалась за рахунок зміни результуючої кінетичної енергії руху центра мас.

J. Gomez-Ezeiza зі співавт. [31] встановили, що більш економні спортсмени, які спеціалізуються у спортивній ходьбі, володіють розвиненою нервово-м'язовою системою, яка оптимально скоординована для зниження метаболічних потреб. Встановлено важливість активації «задніх» м'язів ноги (великого сід- ничного м'яза $-p=0,022, r=0,716$; двоголового м'яза стегна - $p=0,011$, $r=0,801 ;$ медіального литкового м'яза - $p=0,041, r=0,662)$ при кінцевому замаху та початковому контакті з землею, що відмічається в ефективному перенесенні енергії (полегшення сили реакції опори) та, як наслідок, в оптимальній біомеханіці суглобів (розгинання та стабілізація стегна). Також виявлено, що спортсмени під час замаху з більшою активністю прямого м'яза стегна ( $p=0,021, r=0,798)$ показали кращу економічність рухів.

У ході навчання і подальшого вдосконалення техніки спортивної ходьби важливо, щоб напружувалися і скорочувалися тільки ті м'язи, які повинні брати участь у русі в певний момент, а інші мають бути розслаблені, інакше не можна економніше і правильно виконувати всі рухи.

A. Drake зі співавт. [26] встановили, що у спортсменів високої кваліфікації V0 $\max$ збільшується приблизно на $20 \%$ після тренувань на витривалість, виділяючи великий генетичний компонент до цього показника, тоді як швидкість в точці повороту лактату (v-LTP, анаеробний поріг) зростає між 40 і $100 \%$, припускаючи, що V-LTP піддається тренуванню, як i v-VO $\max$, здебільшого завдяки його економічній складовій. Ефективність впливу реакції v-LTP та V-VO $\max$ на тренування зі спортивної ходьби гідна досліджень; крім того, роль біомеханіки спортивної ходьби у варіації економічності вимагає подальших досліджень. Слід зазначити, що витривалість у спортсменів, які спеціа- 
лізуються у спортивній ходьбі, більше корелює 3 лактатними змінними, ніж $\mathrm{VO}_{2} \max$.

у результаті досліджень 0. Espinoza-Navarro зі співавт. [27] соматотипу спортсменів на Панамериканському кубку зі спортивної ходьби на 20 км встановлено, що в атлетів високого рівня (рівень результатів 1:22.40) спостерігався більший ектоморфний компонент ( $p<0,05)$, ніж у атлетів нижчої кваліфікації (рівень результатів 1:32.41). При цьому більш кваліфріковані спортсмени мали вищий зріст $178,3 \pm 4,4$ см проти 173,7 $\pm 5,6 \mathrm{~cm}$ $(p<0,05)$.

J. Brod'ani, P. Šelinger, M. Vavak [21], аналізуючи техніку провідних спортсменів країни, виявили проблему амбідекстрії (відсутність явно вираженої асиметрії) та встановили тісну залежність зі стажем тренування. При цьому важливим аспектом удосконалення технічної майстерності вважають у покращенні міжм'язової та внутрішньом'язової координації та використання гнучких рухів кінетичної системи організму. Спортивна підготовка, орієнтована на розвиток особливих силових здібностей, допоможе атлетам підвищити кінетичну економічність, а також її ефективність.

Результати досліджень С. B. Tucker та B. Hanley [51] також підтверджують взаємозв'язок симетрії рухів 3 рівнем кваліфікації спортсмена. Провівши тестування спортсменів високого світового рівня на різних швидкостях виконання спортивної ходьби, вони встановили відсутність чітко вираженої асиметрії та варіативності рухів у спортивній ходьбі.

D. Cazzola, G. Pavei, E. Preatoni [23], провівши дослідження зі спортсменами елітного, міжнародного та національного рівня на різних швидкостях пересування - 12 та 15,5 км · год ${ }^{-1}$, встановили, що в атлетів національного рівня $з$ підвищенням швидкості рухів спостерігається більша варіативність за основними біомеханічними показниками, ніж у спортсменів елітного та міжнародного рівнів.

Результати досліджень S. Amara, B. Mkaouer [20] у жінок світового рівня на різних швидкостях пересування - 13,2 та 15,12 км · год ${ }^{-1}$ (остання знаходиться на рівні чоловіків високого світового рівня) - показали відносну стабільність техніки за основними кінематичними характеристиками, однак збільшення довжини кроку спостерігалось за рахунок «зорового» збільшення польоту.

Результати досліджень J. GomezEzeiza зі співавт. [30], проведені зі спортсменами високого світового рівня, які спеціалізуються на дистанції 20 км, свідчать, що економічність спортивної ходьби (спортсмени демонстрували знижене споживання кисню) пов'язана 3 тривалішим часом контакту з землею, коротшим часом польоту, більш тривалою фазою амортизації і більш короткою фазою активного відштовхування. Тому тренерам і спортсменам слід уникати зміни свого стилю спортивної ходьби шляхом збільшення часу польоту, оскільки це не тільки знижує економічність рухів, але й може призвести до дискваліфікації.

Дискусія. Сьогодні автори приділяють значну увагу вивченню кінематичних та динамічних характеристик техніки спортсменів високої кваліфікації, пошуку шляхів економізації їхньої техніки. Проте ці дослідження практично не пов'язані з педагогічною складовою (засобами та методами) формування та удосконалення технічної майстерності спортсменів, які спеціалізуються у спортивній ходьбі.

Однак спортивна практика не стоїть на місці: вводяться нові дистанції на найбільших світових форумах (30крема 50 км у жінок; 35 км у чоловіків та жінок), збільшується рівень спортивних результатів, розширюються тактичні варіанти ведення змагальної боротьби провідними спортсменами світу, що висуває нові вимоги до техніки виконання змагальної вправи та технічної підготовки не тільки атлетів високої кваліфрікації, а й спортсменів, які знаходяться на початковому та базових етапах багаторічної підготовки.

Практично відсутні дані щодо техніки спортсменок, які спеціалізуються на дистанції 50 км, а також 35 км у чоловіків та жінок. Мало вивченими залишаються питання техніки спортсменів на етапах попередньої та спеціалізованої базової підготовки. Разом з тим модельні показниками техніки ходьби у спеціальній літературі представлені фррагментарно. В основному вони стосуються узагальнених середніх даних [32, 40], або прогностично змодельованих основних характеристик (довжини та частоти кроків) [10], чи певних індивідуальних характеристик переважно спортсменів-юніорів та дорослих атлетів [34, 37].

Висновки. Аналіз даних науковометодичної літератури свідчить про наявність фундаментальних теоретико-методичних основ техніки спортивної ходьби. Однак сьогодні відсутні фундаментальні узагальнюючі роботи, присвячені удосконаленню технічної підготовки у процесі багаторічного удосконалення легкоатлетів, які спеціалізуються у спортивній ходьбі. Проаналізовані дослідження, безумовно, створюють фрундаментальну базу для удосконалення технічної підготовки у спортивній ходьбі у процесі всієї багаторічної підготовки. Однак вони портребують розширення, систематизації, узагальнення та інтерпретації з позиції насамперед педагогічної складової побудови багаторічного тренувального процесу.

Конфлікт інтересів. Автор заявляє що відсутній будь-який конфлікт інтересів.

\section{ЛІТЕРАТУРА}

1. Абзалов РА. Тупики и перспективы раз вития методов спортивной подготовки в циклических видах легкой атлетики. Теория и практика фриз. культуры. 2000;(11):23-28.

2. Артюшенко ОФ. Легка атлетика. Теорія і методика викладання: [навч. посіб.]. Черкаси: Брама-Україна; 2008. 632 с.

3. Бернштейн НА. 0 ловкости и ее развитии. Москва: Физкультура и спорт; 1991. 288 с.

4. Бобровник ВИ. Совершенствование технического мастерства спортсменов высокой квалификации в легкоатлетических соревновательных прыжках: монография. Киев: Науковий світ; 2005. 322 с.

5. Бобровник ВИ, Совенко СП, Колот АВ, редакторы. Легкая атлетика: учебник. Киев: Логос; 2017. 759 с.

6. Бондаренко СК. Спортивная ходьба: Техника. Методика. Тактика. Санкт-Петербург ЦлПС; 1993. 96 с.

7. Гамалий ВВ. Моделирование техники двигательных действий в спорте (на примере ходьбы). Наука в олимпийском спорте. 2005;(2):108-116.

8. Зеличенок ВБ. Поиск легкоатлетических талантов: набор или отбор? практические рекомендации. Современные тенденции развития лёгкой атлетики в мире: спорт высших достижений и подготовка резерва (за два года до 
Олимпийских игр в г. Токио). В: Зеличенок ВБ Мирзоев ОМ, редакторы. Сборник научно методических материалов II Всеросс. научно практ. конф., посвященной 100-летию образо вания Российского государственного университета физической культуры, спорта, молодёжи и туризма (ГЦОЛИФК); Москва. Москва: НОУ РГУФКСМиТ; 2018. с. 5-18.

9. Калитка С, Яловик В, Боровская Н, Калитка Н. Гендерные особенности техники спортивной ходьбы. Фізичне виховання, спорт культура здоров'я у сучасному суспільстві: зб. наук. праць Волин. нац. ун-ту ім. Лесі Українки. 2009;(2):91-95

10. Королев ГИ. Управление системой подготовки в спорте. На примере подготовки в спортивной ходьбе. Москва: Мир атлетов; 2005 192 C.

11. Полозков АГ. Параметры шага Ольги Канискиной - чемпионки мира по спортивной ходьбе 2011 г. Теория и практика фриз. культу ры. 2015;(2):73-75

12. Правила змагань 2020-2021. 180 с. До ступно: http://uaf.org.ua/statistics/books/iaaf_ rules_2018-2019.html

13. Совенко С. Технико-тактические особенности преодоления дистанции в спортив ной ходьбе. Наука в олимпийском спорте 2020;(1):81-90.

14. Совенко СП, Будкевич ГБ, Литвинчук ТВ. Характеристики техники квалифицированных спортсменок, специализирующихся в спортивной ходьбе на 10 км. Физическое воспитание студентов. 2014;(4):37-41.

15. Совенко СП, Андрущенко ЮМ, Соло мін AB, Виноградов ВЄ. Спортивна ходьба: навч. посіб. Київ: ТОВ «НВФ «Славутич-Дельфін» 2018. 144 c.

16. Тюпа ВВ, Аракелян ЕЕ, Примаков ЮН Биомеханические основы техники спортивной ходьбы и бега. Москва: Олимпия; 2009. 64 с.

17. Фруктов АЛ, Травин ЮГ. Основы техни ки ходьбы. Спортивная ходьба. В: Озолин НГ, Воронкин ВИ, Примаков ЮН, редакторы. Легкая атлетика: учеб. для ин-тов физ. культуры. Москва: Физкультура и спорт; 1989. с. 37-41, 312-334

18. Alves DL, Cruz R, Lima-Silva AE, Domin gos PR, Osiecki R, De-Oliveira FR, Lima JRP. Do warnings received in race walking influence the speed o $f$ athletes? International Journal of Performance Analysis in Sport. 2018;18(3):463-469 Available from: https://www.researchgate.net/publication/326221926_Do_warnings_received_in race_walking_influence_the_speed_of_athletes DOl: https://doi.org/10.1080/24748668.2018.148 8438

19. Alves DL, Cruz R, Lima-Silva AE, Domingos PR, Bertuzzi R, Osiecki R, et al. Are experienced and high-level race walking athletes able to match pre-programmed with executed pacing? Brazilian Journal of Medical and Biological Research. 2019;52(6). DOI: http://dx.doi.org/10.1590/1414 $431 \times 20198593$

20. Amara S, Mkaouer B. Effect of speed change on the kinematic parameters of women's $20 \mathrm{~km}$ racewalking: A case study. Journal of Physical Education and Sport. 2020;20:2061-2067. DOI:10.7752/jpes.2020.3278.

21. Brod'ani J, Šelinger P, Vavak M. Athletic walking in terms of kinematic parameters of walking step. World race walking research: Monograph. Martin Pupi Š et al. 2011. p. 162-170.

22. Caporaso T, Grazioso S. IART: Inertial Assistant Referee and Trainer for Race Walking. Sensors. 2020;20(3):30 p. DOI: 10.3390/s20030783
23. Cazzola D, Pavei G, Preatoni E Can coordination variability identify performance factors and skill level in competitive sport? The case of race walking. Journal of Sport and Health Science. 2016;5(1):35-43. DOI: https://doi.org/10.1016/j. jshs.2015.11.005

24. Chwała W, Klimek A, Mirek W. Changes in Energy Cost and Total External Work of Muscles in Elite Race Walkers Walking at Different Speeds. Journal of Human Kinetics. 2014;44(1):129-136. DOI: 10.2478/hukin-2014-0118

25. Dona G, Preatoni E, Cobelli C, Rodano $R$, Harrison A. Application of functional principal component analysis in race walking: $A$ emerging methodology. Sports Biomechanics. 2009;8(4):284-301. Available from: https://www. researchgate.net/publication/41506545_Application_of_functional_principal_component_analysis in race_walking_An_emerging_methodology DOI: $10.1080 / 14763140903414425$

26. Drake A, James R, Cox V, Godfrey R, Brooks S. Physiological Variables Related to 20 $\mathrm{km}$ Race Walk Performance. Journal of Sports Sciences. 2003; 21(4):269-270. Available from: http://www.surreywalkingclub.org.uk/Coaching/ Physiological\%20variables\%20related $\% 20$ to $\% 20$ $20 \% 20 \mathrm{~km}$.pdf

27. Espinoza-Navarro 0, Lizana PA, GómezBruton A, Brito-Hernández L, Lagos-Olivos CS Anthropometric Characteristics, Body Composition and Somatotype of Elite Pan-American Race Walking 20K. International Journal of Morpho logy. 2019;37(4):1220-1225. DOI: 10.4067/ S0717-95022019000401220

28. Gironimoa G, Caporasoa T, Amodeob G Giudicea DMD, Taralloa A, Lanzotti A. Development of a new experimental protocol for analysing the Race-walking technique based on kinematic and dynamic parameters. 11th conference of the International Sports Engineering Association, ISEA 11-14 JUL; 2016. p. 741-746. DOI: https://doi. org/10.1016/j.proeng.2016.06.236

29. Gong M, Dang S. The Changing Rule and Development Trends of Technical Action during the Excellent Teenager Women's Race Walking Training Time. 9th China National Convention on Sport Science. DEC 01-04; 2011. p. 468-471.

30. Gomez-Ezeiza J, Torres-Unda J, Tam N Irazusta J, Granados C, Santos-Concejero J. Race walking gait and its influence on race walking economy in world-class race walkers. Journal of Sports Sciences. 2018; 36(19):2235-2241. Available from: https://www.researchgate.net/ publication/281780531_Kinetic_analysis_of_the function_of_the_upper_body_for_elite_race walkers_during offcial_men_20_km walking race DOI: https://doi.org/10.1080/02640414.2018 1449086

31. Gomez-Ezeiza J, Santos-Concejero J, Torres-Unda J, Hanley B, Tam N. Muscle activation patterns correlate with race walking economy in elite race walkers: a waveform analysis. International Journal of Sports Physiology and Performance. 2019;14(9):1250-1255. Available from: https://www.researchgate.net/publication/331693514 Muscle Activation_Patterns Correlate_With_Race_Walking_Economy_in Elite_Race_Walkers_A_Waveform_Analysis DOI: https://doi.org/10.1123/ijspp.2018-0851

32. Hanley BS. Biomechanical analysis of elite race walking [dissertation]. Leeds Metropolitan University; 2014. 303 p

33. Hanley B, Bissas A. Ground reaction forces of Olympic and World Championship race walkers. Eur. J. Sport Sci. 2016;16:50-56.

34. Hanley B, Drake A, Bissas A. The biomechanics of elite race walking: technique analysis and the effects of fatigue. New studies in athletics. 2008; (4):17-25.

35. Hanley B, Bissas A, Drake A. Initial findings of a biomechanical analysis at the 2008 IAAF World Race Walking Cup. New studies in athletics. 2008;(4):27-34

36. Hanley B, Drake A, Bissas A. Kinematic characteristics of elite men's $50 \mathrm{~km}$ race walking. European Journal of Sport Science. 2013;13(3):272279. DOI: $10.1080 / 17461391.2011 .630104$

37. Hanley B, Bissas A, Drake A. Technical characteristics of elite junior men and women race walkers. The Journal of sports medicine and physical fitness. 2014;54(6):700-707

38. Harrison AJ, Patrick GM, Furlong L-AM. Does the McNeill Alexander model accurately predict maximum walking speed in novice and experienced race walkers? Journal of Sport and Health Science. 2018;7(3):372-377. DOI: https:// doi.org/10.1016/j.jshs.2016.04.010

39. Hoga-Miura K, Michiyoshi AE, Fujii N, Yokozawa T. Kinetic analysis of the function of the upper body for elite race walkers during official men $20 \mathrm{~km}$ walking race. Journal of Sports Medicine and Physical Fitness. 2016;56(10):11471155. Available from: https://www.researchgate. net/publication/281780531_Kinetic_analysis_ of the_function_of_the_upper_body_for_elite race_walkers_during_offcial_men_20_km_walking_race

40. Hoga-Miura K, Hirokawa R, Sugita M. Reconstruction of Walking Motion without Flight Phase by Using Computer Simulation on the World Elite $20 \mathrm{~km}$ Race Walkers During Official Races. Slovak Journal of Sport Science. 2017;2(1):5975. Available from: https://www.researchgate.net/ publication/340683934_Reconstruction_of_walking_motion_without_flight_phase_by_using_ computer_simulation_on_the_world_elite_20km_ race_walkers_during_official_races_Slovak_Journal of Sport Science

41. Hoga-Miura K, Hirokawa R, Sugita M. A three-dimensional kinematic analysis of walking speed on world elite women's 20-km walking races using an inverted pendulum model. Gazzetta Medica Italiana Archivio per le Scienze Mediche. 2020;179(1-2):29-38. Available from: https://www. researchgate.net/publication/340450617 A threedimensional_kinematic_analysis_of_walking_ speed_on_world_elite_women's_20-km_walking races_using an inverted_pendulum model DOI: 10.23736/S0393-3660.18.04009-3

42. Jelonek J, Pilis W, Świat M, Michalski C, Stec K. Quality of sports training and the biological adaptation of athletes to race walking. Physical Activity Review. 2017;5:212-221. D0I: http://dx.doi. org/10.16926/par.2017.05.26

43. Lee JB, Mellifont RB, Burkett BJ, James DA. T Detection of Illegal Race Walking: A Tool to Assist Coaching and Judging. Sensors. 2013;13(12):16065-16074. DOI: 10.3390/ s131216065

44. Norberg J, Schmitz A. Is Race Walking Lower Impact Than Running? ASME International Mechanical Engineering Congress and Exposition (IMECE2016). - November 11-17; Phoenix, Arizona, USA; 2016.3. p. 4 Available from: thtps:// www.researchgate.net/publication/313625727 Is_Race_Walking_Lower_Impact_Than_Running DOI:10.1115/IMECE2016-65126

45. Pavei G, Cazzola D, La Torre A, Minetti $A E$. The biomechanics of race walking: Literature overview and new insights. European Journal of Sport Science. 2014;14(7):661-670. Available from: https://www.researchgate.net/publication/259805320_The biomechanics_of race 
walking_Literature_overview_and_new_insights DOI: 10.1080/17461391.2013.878755

46. Pavei G, Cazzola D, La Torre A, Minetti AE. Race Walking Ground Reaction Forces at Increasing Speeds: A Comparison with Walking and Running. Symmetry-Basel. 2019;11(7):11 p. DOI: 10.3390/sym 11070873

47. Pavlović R, Petrović B, Vrcić M. Race Walking: Inversion of Function From the Aspect of Speed and Result Success. European Journal of Physical Education and Sport Science. 2021;6(11):59-70. DOI: 10.46827/ejpe.v6i11.3611

48. Sovenko S. Technique and Tactics of Elite Male Race Walkers. New studies in athletics. 2016;(3-4):91-100.

49. Sun W, Zhang L, Fan A. Biomechanical Analysis on Hip-push Skills Applied in Walking Race. International Conference on Future Computer Supported Education. 22-23 AUG; 2012;2:264269. DOI: $10.1016 /$ j.ieri.2012.06.086

50. Taborri J, Palermo E, Rossi S. Automatic Detection of Faults in Race Walking: A Comparative Analysis of Machine-Learning Algorithms Fed with Inertial Sensor Data. Sensors. 2019;19(6):1-19 DOI: 10.3390/s19061461

51. Tucker CB, Hanley B. Increases in speed do not change gait symmetry or variability in world-class race walkers. Journal of Sports Sciences. 2020;38(24):2758-2764. DOl: https://doi. org/10.1080/02640414.2020.1798730

52. Vernillo G, Piacentini MF, Drake A Agnello L, Fiorella P, La Torre A. Exercise Intensity and Pacing Strategy of a 5-km Indoor Race Walk During a World Record Attempt: A Case Study. Journal of Strength and Conditioning Research. 2011;25(7):2048-2052. DOI: 10.1519/ JSC.0b013e3181e4f78e

53. Wei Y, Liu L, Zhong J, Lu Y, Sun L. Unsupervised Race Walking Recognition Using Smartphone Accelerometers. 8th International Conference, KSEM 2015, Chongqing, China, October 28-30; 2015. p. 691-702. Available from: https://link.springer.com/chapter/10.1007/978-3-319-25159-2_63

\section{LITERATURE}

1. Abzalov RA. Dead ends of and prospects for the development of sports training methods in cyclic track and field sports. Theory and practice of physical culture. 2000;(11):23-28.

2. Artyushenko OF. Track and field athletics Theory and methodology of teaching: [study guide]. Cherkasy: Brama-Ukraina; 2008. 632 p.

3. Bernshtein NA. About agility and its development. Moscow: Fizkultura i sport; 1991. $288 \mathrm{p}$.

4. Bobrovnik VI. Improving the technical skills in elite athletes competing in athletic jump events: monograph. Kiev: Naukovyi svit; 2005. 322 p.

5. Bobrovnik VI, Sovenko SP, Kolot AV, editors. Track and field athletics: textbook. Kiev: Logos; 2017. 759 p.

6. Bondarenko SK. Race walking: Technique. Methodology. Tactics. Saint Petersburg: TsLPS; 1993; 96 p.

7. Gamaliy VV. Modeling the technique of motor actions in sports (as exemplified by walking). Science in Olympic sport. 2005;(2):108116.

8. Zelichenok VB. Searching for a trackand-field talent: recruitment or selection? practical recommendation. Current trends in the development of athletics in the world: highperformance sport and reserve preparation (two years before the Olympic Games in Tokyo). In:
Zelichenok VB, Mirzoev OM, editors. Proceedings of II All-Russian scientific and practical conf dedicated to the 100th anniversary of the formation of the Russian State University of Physical Culture Sports, Youth and Tourism; Moscow. Moscow: NOU RGUFKSMiT; 2018. P. 5-18.

9. Kalitka S, Yalovik V, Borovskaya N Kalitka N. Gender characteristics of racewalking technique. Physical education, sport and health culture in modern society: Collection of scientific papers of the Lesya Ukrainka Volyn National University. 2009;(2):91-95

10. Kotolev GI. Management of the training system in sports. As exemplified by race walking Moscow: Mir atletov; 2005. 192 p.

11. Polozkov AG. Step Characteristics of Olga Kaniskina - World Race Walking Champion 2011. Theory and practice of physical culture. 2015;(2):73-75

12. The rules of competitions 2020-2021. 180 p. Retrieved from: http://uaf.org.ua/statistics/ books/iaaf_rules_2018-2019.html

13. Sovenko S. Technico-tactical peculiarities of distance covering in race walking. Science in Olympic sport. 2020;(1):81-90

14. Sovenko SP, Budkevich GB, Litvinchuk TV. Characteristics of technique of qualified female athletes specializing in $10 \mathrm{~km}$ race walking. Physical education of students. 2014;(4):37-41.

15. Sovenko SP, Andrushchenko YuM Solomin AV, Vynogradov VYe. Race walking: study guide. Kyiv: TOV "NVF "Slavutych-Delfin"; 2018 $144 \mathrm{p}$.

16. Tyupa VV, Arakelyan EE, Primakov YuN Biomechanical fundamentals of race walking and running techniques. Moscow: Olimpiya; 2009; 64 p.

17. Fruktov AL, Travin YuG. Fundamentals of race walking technique. Race walking. In: Ozolin NG, Voronkin VI, Bobrovnik VI, Primakov YuN editors. Track and field athletics: textbook for physical culture institutes. Moscow: Fizkultura sport; 1989. P. 37-41, 312-334.

18. Alves DL, Cruz R, Lima-Silva AE, Domin gos PR, Osiecki R, De-Oliveira FR, Lima JRP. Do warnings received in race walking influence the speed $0 \mathrm{f}$ athletes? International Journal of Per formance Analysis in Sport. 2018;18(3):463-469. Available from: https://www.researchgate.net/publication/326221926_Do_warnings_received_in race walking influence the speed of athletes DOl: https://doi.org/10.1080/24748668.2018.148 8438

19. Alves DL, Cruz R, Lima-Silva AE, Domin gos PR, Bertuzzi R, Osiecki R, et al. Are experience and high-level race walking athletes able to match pre-programmed with executed pacing? Brazi lian Journal of Medical and Biological Research. 2019;52(6). DOI: http://dx.doi.org/10.1590/1414 $431 \times 20198593$

20. Amara S, Mkaouer B. Effect of speed change on the kinematic parameters of women's $20 \mathrm{~km}$ racewalking: A case study. Journal of Physical Education and Sport. 2020;20:2061-2067. DOI:10.7752/jpes.2020.3278.

21. Brod'ani J, Selinger P, Vavak M. Athletic walking in terms of kinematic parameters of walking step. World race walking research: Monograph. Martin Pupi Š et al. 2011. p. 162-170.

22. Caporaso T, Grazioso S. IART: Inertial Assistant Referee and Trainer for Race Walking. Sensors. 2020;20(3):30 p. DOI: 10.3390/s20030783

23. Cazzola D, Pavei G, Preatoni E. Can coordination variability identify performance factors and skill level in competitive sport? The case of race walking. Journal of Sport and Health Science.
2016;5(1):35-43. DOI: https://doi.org/10.1016/j. jshs.2015.11.005

24. Chwała W, Klimek A Mirek W. Changes in Energy Cost and Total External Work of Muscles in Elite Race Walkers Walking at Different Speeds Journal of Human Kinetics. 2014;44(1):129-136. DOI: 10.2478/hukin-2014-0118

25. Dona G, Preatoni E, Cobelli C, Rodano $R$, Harrison A. Application of functional principal component analysis in race walking: An emerging methodology. Sports Biomechanics. 2009;8(4):284-301. Available from: https://www. researchgate.net/publication/41506545_Application_of_functional_principal_component_analysis_in_race_walking_An_emerging_methodology DOI: $10.1080 / 14763140903414425$

26. Drake A, James R, Cox V, Godfrey R Brooks S. Physiological Variables Related to 20 km Race Walk Performance. Journal of Sports Sciences. 2003; 21(4):269-270. Available from http://www.surreywalkingclub.org.uk/Coaching/ Physiological\%20variables $\% 20$ related $\% 20$ to $\% 20$ $20 \% 20 \mathrm{~km}$.pdf

27. Espinoza-Navarro 0, Lizana PA, GómezBruton A, Brito-Hernández L, Lagos-Olivos CS Anthropometric Characteristics, Body Composition and Somatotype of Elite Pan-American Race Walking 20K. International Journal of Morphology. 2019;37(4):1220-1225. DOI: 10.4067/ S0717-95022019000401220

28. Gironimoa G, Caporasoa T, Amodeob G, Giudicea DMD, Taralloa A, Lanzotti A. Development of a new experimental protocol for analysing the Race-walking technique based on kinematic and dynamic parameters. 11th conference of the International Sports Engineering Association, ISEA 11-14 JUL; 2016. p. 741-746. DOI: https://doi org/10.1016/j.proeng.2016.06.236

29. Gong M, Dang S. The Changing Rule and Development Trends of Technical Action during the Excellent Teenager Women's Race Walking Training Time. 9th China National Convention on Sport Science. DEC 01-04; 2011. p. 468-471.

30. Gomez-Ezeiza J, Torres-Unda J, Tam N Irazusta J, Granados C, Santos-Concejero J. Race walking gait and its influence on race walking economy in world-class race walkers. Journa of Sports Sciences. 2018; 36(19):2235-2241. Available from: https://www.researchgate.net/ publication/281780531_Kinetic_analysis_of_the function_of_the_upper_body_for_elite_race_ walkers_during_offcial_men_20_km_walking race DOI: https://doi.org/10.1080/02640414.2018 .1449086

31. Gomez-Ezeiza J, Santos-Concejero J Torres-Unda J, Hanley B, Tam N. Muscle activation patterns correlate with race walking economy in elite race walkers: a waveform analysis International Journal of Sports Physiology and Performance. 2019;14(9):1250-1255. Available from: https://www.researchgate.net/publica tion/331693514_Muscle_Activation_Patterns_ Correlate_With_Race_Walking_Economy_in Elite_Race_Walkers_A_Waveform_Analysis DOI: https://doi.org/10.1123/ijspp.2018-0851

32. Hanley BS. Biomechanical analysis of elite race walking [dissertation]. Leeds Metropolitan University; 2014. 303 p

33. Hanley B, Bissas A. Ground reaction forces of Olympic and World Championship race walkers Eur. J. Sport Sci. 2016;16:50-56.

34. Hanley B, Drake A, Bissas A. The biome chanics of elite race walking: technique analysis and the effects of fatigue. New studies in athletics. 2008; (4):17-25.

35. Hanley B, Bissas A, Drake A. Initial findings of a biomechanical analysis at the 2008 IAAF 
World Race Walking Cup. New studies in athletics. 2008;(4):27-34

36. Hanley B, Drake A, Bissas A. Kinematic characteristics of elite men's $50 \mathrm{~km}$ race walking. European Journal of Sport Science. 2013;13(3):272279. DOI: $10.1080 / 17461391.2011 .630104$

37. Hanley B, Bissas A, Drake A. Technical characteristics of elite junior men and women race walkers. The Journal of sports medicine and physical fitness. 2014;54(6):700-707.

38. Harrison AJ, Patrick GM, Furlong L-AM Does the McNeill Alexander model accurately predict maximum walking speed in novice and experienced race walkers? Journal of Sport and Health Science. 2018;7(3):372-377. DOI: https://

39. Hoga-Miura K, Michiyoshi AE, Fujii N, Yo kozawa T. Kinetic analysis of the function of the upper body for elite race walkers during officia men 20 km walking race. Journal of Sports Medicine and Physical Fitness. 2016;56(10):1147-1155 Available from: https://www.researchgate.net/ publication/281780531_Kinetic_analysis_of_the_ function of the upper body for elite race walkers_during_offcial_men_20_km_walking race

40. Hoga-Miura K, Hirokawa R, Sugita M Reconstruction of Walking Motion without Flight Phase by Using Computer Simulation on the World Elite 20 km Race Walkers During Official Races. Slovak Journal of Sport Science. 2017;2(1):59 75. Available from: https://www.researchgate.net/ publication/340683934_Reconstruction_of_walkdoi.org/10.1016/j.jshs.2016.04.010

ing_motion_without_flight_phase_by_using computer_simulation_on_the_world_elite_20km race_walkers_during_official_races_Slovak_Jour nal_of_Sport_Science

41. Hoga-Miura K, Hirokawa R, Sugita M. A three-dimensional kinematic analysis of walking speed on world elite women's 20 $\mathrm{km}$ walking races using an inverted pendulum model. Gazzetta Medica Italiana Archivio pe le Scienze Mediche. 2020;179(1-2):29-38 Available from: https://www.researchgate.net/ publication/340450617_A_three-dimensional_kinematic_analysis_of_walking_speed_on_world elite women's 20-km walking races using an_inverted_pendulum_model DOI: 10.23736 S0393-3660.18.04009-3

42. Jelonek J, Pilis W, Świat M, Michalski C Stec K. Quality of sports training and the biologica adaptation of athletes to race walking. Physical Activity Review. 2017;5:212-221. DOl: http://dx.doi. org/10.16926/par.2017.05.26

43. Lee JB, Mellifont RB, Burkett BJ, James DA. T Detection of Illegal Race Walking A Tool to Assist Coaching and Judging. Sensors. 2013;13(12):16065-16074. DOI: 10.3390/ s131216065

44. Norberg J, Schmitz A. Is Race Walking Lower Impact Than Running? ASME Internationa Mechanical Engineering Congress and Exposition (IMECE2016). - November 11-17; Phoenix Arizona, USA; 2016.3. p. 4 Available from: thtps:// www.researchgate.net/publication/313625727

\section{ІНФОРМАЦІЯ ПРО АВТОРА}

Совенко Сергій Петрович https://orcid.org/0000-0001-9996-4712, E-mail: sovenkos@ukr.net Національний університет фізичного виховання і спорту України 03150, Київ, вул. Фізкультури, 1

\section{INFORMATION ABOUT THE AUTHOR}

Sovenko Serhii https:orcid.org/0000-0002-8862-9545, https://orcid.org/0000-0001-9996-4712 E-mail: sovenkos@ukr.net

National University of Ukraine on Physical Education and Sport 03150, Kyiv, Fizkul'tury str., 1.
Is Race Walking Lower Impact Than Running DOI:10.1115/IMECE2016-65126

45. Pavei G, Cazzola D, La Torre A, Minetti $A E$. The biomechanics of race walking: Literature overview and new insights. European Journal of Sport Science. 2014;14(7):661-670. Available from: https://www.researchgate.net/publication/259805320 The biomechanics of race walking_Literature_overview_and_new_insights DOl: 10.1080/17461391.2013.878755

46. Pavei G, Cazzola D, La Torre A, Minetti AE. Race Walking Ground Reaction Forces at Increasing Speeds: A Comparison with Walking and Running. Symmetry-Basel. 2019;11(7):11 p. DOl: 10.3390/sym 11070873

47. Pavlović R, Petrović B, Vrcić M. Race Walking: Inversion of Function From the Aspect of Speed and Result Success. European Journal of Physical Education and Sport Science. 2021:6(11):59-70. DOI: 10.46827/ejpe.v6i11.3611

48. Sovenko S. Technique and Tactics of Elite Male Race Walkers. New studies in athletics. 2016;(3-4):91-100

49. Sun W, Zhang L, Fan A. Biomechanical Analysis on Hip-push Skills Applied in Walking Race. International Conference on Future Computer Supported Education. 22-23 AUG; 2012;2:264269. DOI: $10.1016 /$ j.ieri.2012.06.086

50. Taborri J, Palermo E, Rossi S. Automatic Detection of Faults in Race Walking: A Comparative Analysis of Machine-Learning Algorithms Fed with Inertial Sensor Data. Sensors. 2019;19(6):1-19 DOI: 10.3390/s19061461

51. Tucker CB, Hanley B. Increases in speed do not change gait symmetry or variability in world-class race walkers. Journal of Sports Sciences. 2020;38(24):2758-2764. DOl: https://doi. org/10.1080/02640414.2020.1798730

52. Vernillo G, Piacentini MF, Drake A, Agnello L, Fiorella P, La Torre A. Exercise Intensity and Pacing Strategy of a 5-km Indoor Race Walk During a World Record Attempt: A Case Study. Journal of Strength and Conditioning Research. 2011;25(7):2048-2052. DOI: 10.1519/JSC.0b013e3181e4f78e

53. Wei Y, Liu L, Zhong J, Lu Y, Sun L. Unsupervised Race Walking Recognition Using Smartphone Accelerometers. 8th International Conference, KSEM 2015, Chongqing, China, October 28-30; 2015. p. 691-702. Available from: https://link.springer.com/ chapter/10.1007/978-3-319-25159-2_63 